

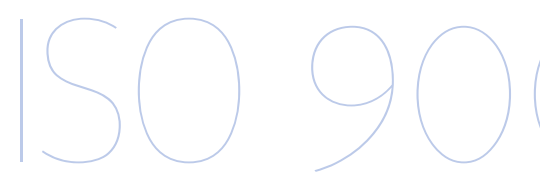

As someone who is involved in the selection of suppliers and, possibly, responsible for making purchasing decisions, you may have seen or used products and services that are promoted using reference to ISO 9001:2015, or, more simply, “ISO 9000”.

What does this mean? How can this help you? How can you be sure that your suppliers understand what you expect from them, and are capable of consistently providing you with products and services that meet your needs and expectations? This informative text provides some answers to these questions and will inform you about how you can get the most out of using ISO 9001 as a supply chain tool. 


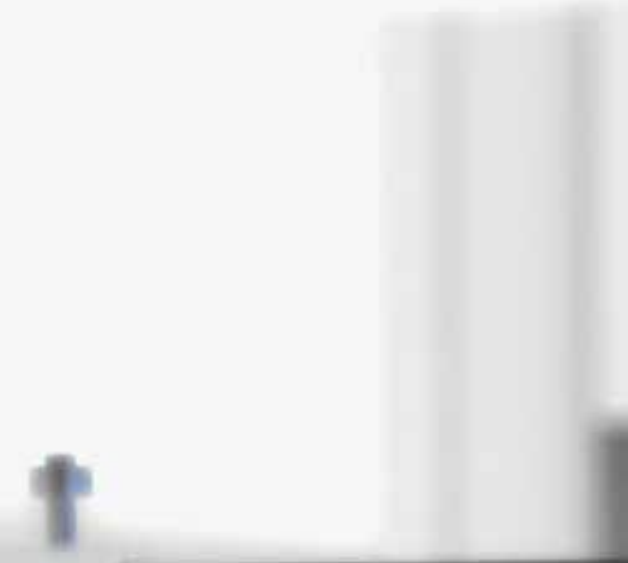

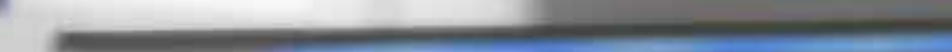

it

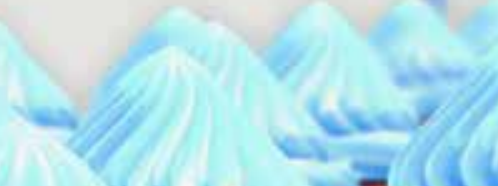

$66=-$

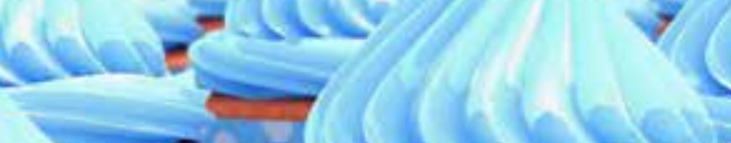

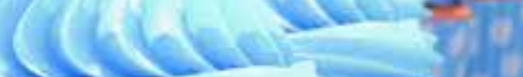

$2-100$

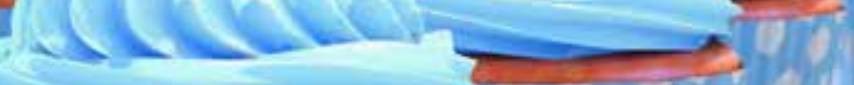

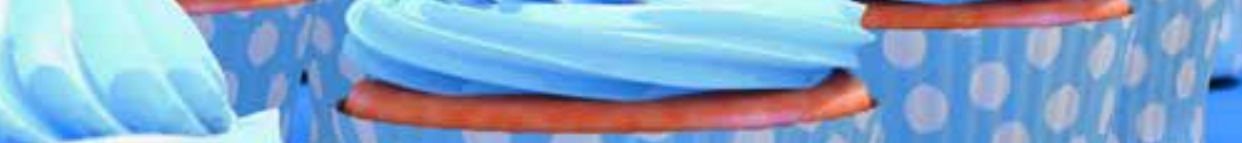
y

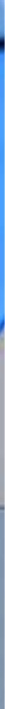




\section{What is ISO 9001?}

ISO 9001 is an International Standard that gives requirements for an organization's quality management system (QMS). It is part of a family of standards published by the International Organization for Standardization (ISO) and often referred to collectively as the “ISO 9000 series” or “ISO 9000 family”.

For this reason, you may sometimes hear your suppliers refer to being "ISO 9000 certified", or having an “ISO 9000-compliant QMS”. This will normally mean that they are claiming to have a QMS that meets the requirements of ISO 9001, the only standard in the ISO 9000 family that can be used for the purpose of conformity assessment. It is important to understand, however, that ISO is the body that develops and publishes the standard - ISO does not “certify” organizations, as will be explained later in this text.

The objective of ISO 9001 is to provide a set of requirements that, if effectively implemented, will give you confidence that your supplier can consistently provide products and services that:

- Meet your needs and expectations

- Comply with applicable regulations 
ISO 9001 adopts a risk-based ("preventive") approach to quality that covers a wide range of topics, including your supplier's top management commitment to quality, its customer focus, the adequacy of its resources, employee competence, process management (for production, service delivery and relevant administrative and support processes), quality planning, design of the products and services it provides, review of incoming orders, purchasing, the appropriate monitoring and measurement of its processes, products and services needed to ensure conformity, its processes to resolve customer complaints, corrective actions, and a requirement to drive improvement. Last but not least, there is a requirement for your supplier to monitor your perceptions about the quality of the products and services it provides to you.

ISO 9001 does not define specific requirements for the products or services you are purchasing. It is up to you to make your own needs and expectations clear to your supplier. You might, for example, refer to product or service specifications, drawings, national or international standards, supplier's catalogues, or other documents as appropriate. 


\section{What does "conformity to ISO 9001 " mean?}

This means that your supplier has established a systematic approach to quality management and is managing its business to ensure that your needs are clearly understood, agreed and fulfilled. A statement of conformity to ISO 9001 should not, however, be considered a substitute for a declaration or statement of product or service conformity.
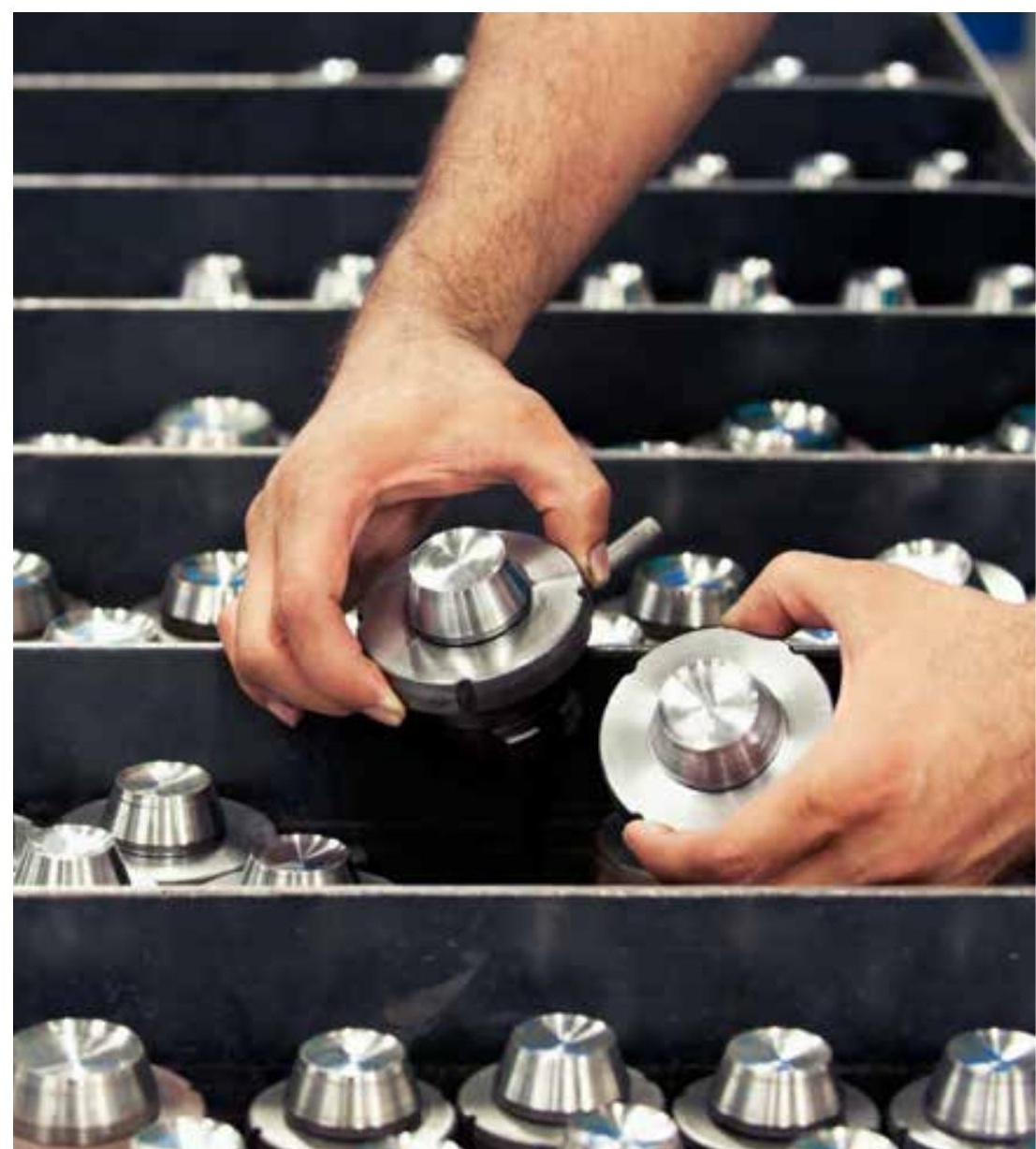


\section{How does}

\section{ISO 9001 help you select a supplier?}

ISO 9001 provides some requirements for the purchasing process that include you as the customer. These requirements address the following topics:

- Requirements regarding the purchasing information that you should provide so that suppliers clearly understand your needs

- Any specific approvals that might be needed to confirm that the supplied products and services meet your requirements, and any monitoring or inspections that you might require at your supplier's premises 
You have an important role to play by specifying to your supplier what you actually want. You may need to consult with your own internal technical staff (the actual users) in this process. If you don't do this, you might find that you receive a product or a service that meets all your stated requirements and the applicable regulatory requirements, but which is absolutely wrong for your intended application. So, first of all, you should concentrate on specifying your needs related to the intended use of the product or service.

To help in this task, you may consider the following :

- What is the specific product or service you are buying?

- What impact does this have on your own business?

- What are the risks to your business if you experience problems with this product or service?

- How can you be sure that the product or service you receive will actually meet your requirements?

- What do you know about the reputation and historical performance of your supplier?

- What level of confidence do you need in your supplier's ability to provide you with conforming products and services on a consistent basis?

- If you decide that conformity to ISO 9001 is important (based on your assessment of the risks associated with the products and services you are buying), how can you be sure that your supplier does have a QMS that meets ISO 9001 requirements?

- Are the products and services you require covered by your supplier's QMS? (You may need to ask for a copy of your supplier's actual certificate or declaration of conformity to find this out!) 


\section{How can you have \\ confidence \\ that your supplier \\ meets ISO 9001?}

There are various ways in which your supplier can claim that its QMS meets the requirements of ISO 9001. These include:

- "Supplier's declaration of conformity": A declaration by your supplier itself affirming that its QMS meets ISO 9001 requirements, usually supported by legally binding signatures. This declaration can be based on your supplier's internal audit system, or on second-party or third-party audits.

- Second-party assessment : Your supplier has been assessed directly by its customer (for example by you, or by another customer whose reputation you respect) to check if its QMS meets ISO 9001 requirements and your own requirements - sometimes used in contractual "business-tobusiness" transactions.

- Third-party assessment (often referred to as certification or registration): Your supplier hires an impartial third party (a certification body or "registrar") to conduct an assessment to verify conformity to ISO 9001 requirements. This third party then issues a certificate to your supplier describing the scope of its QMS, and confirming that it conforms to ISO 9001.

- Additional confidence may be derived from the fact that some certification bodies (registrars) are accredited by nationally or internationally recognized accreditation bodies that verify the certification body's independence and competence to carry out the certification process. Many accreditation bodies have multilateral arrangements under the umbrella of the International Accreditation Forum (IAF) to promote worldwide mutual recognition in support of World Trade Organization (WTO) free trade principles. Figure 1 explains this in simple schematic terms. 


\section{International Accreditation Forum (IAF)}

The IAF is an association of accreditation bodies and other interested parties from around the world, who work together to promote confidence and consistency in the ISO 9001 accreditation and certification process.

\section{Certification body/registrar}

A common way for a supplier to demonstrate conformity to ISO 9001 is via an independent ("third-party") certification process. A certification body (sometimes known as a "registrar") conducts an audit of the supplier and if all is $\mathrm{OK}$, they will issue a certificate of conformity.

\section{Accreditation body}

The accreditation process provides additional confidence that the certification body is competent and has the necessary integrity to issue an ISO 9001 certificate. Accreditation is usually carried out by national or regional accreditation bodies, and their accreditation mark will appear on the certificate.

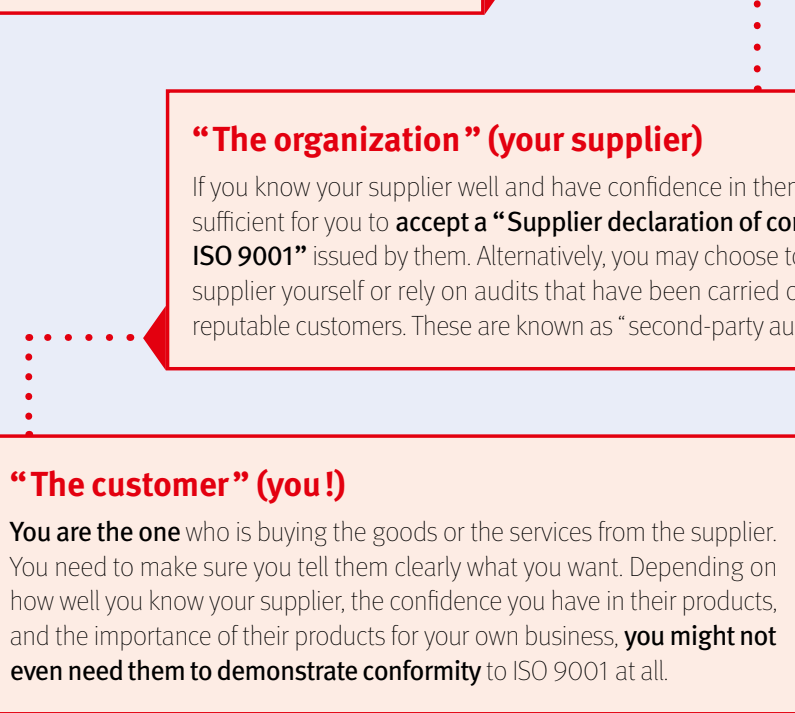

Figure 1 - Some ways of demonstrating conformity to ISO 9001 
Note that ISO 9001 was recently revised (September 2015) and although ISO 9001:2015 incorporates some changes in approach compared with the 2008 edition, the core objectives remain the same and conformity to either version should provide similar levels of confidence in your supplier's QMS. The IAF has defined a "coexistence" period for the two versions of the standard until September 2018, during which time accredited certificates issued against ISO 9001:2008 and ISO 9001:2015 will both be recognized as valid.

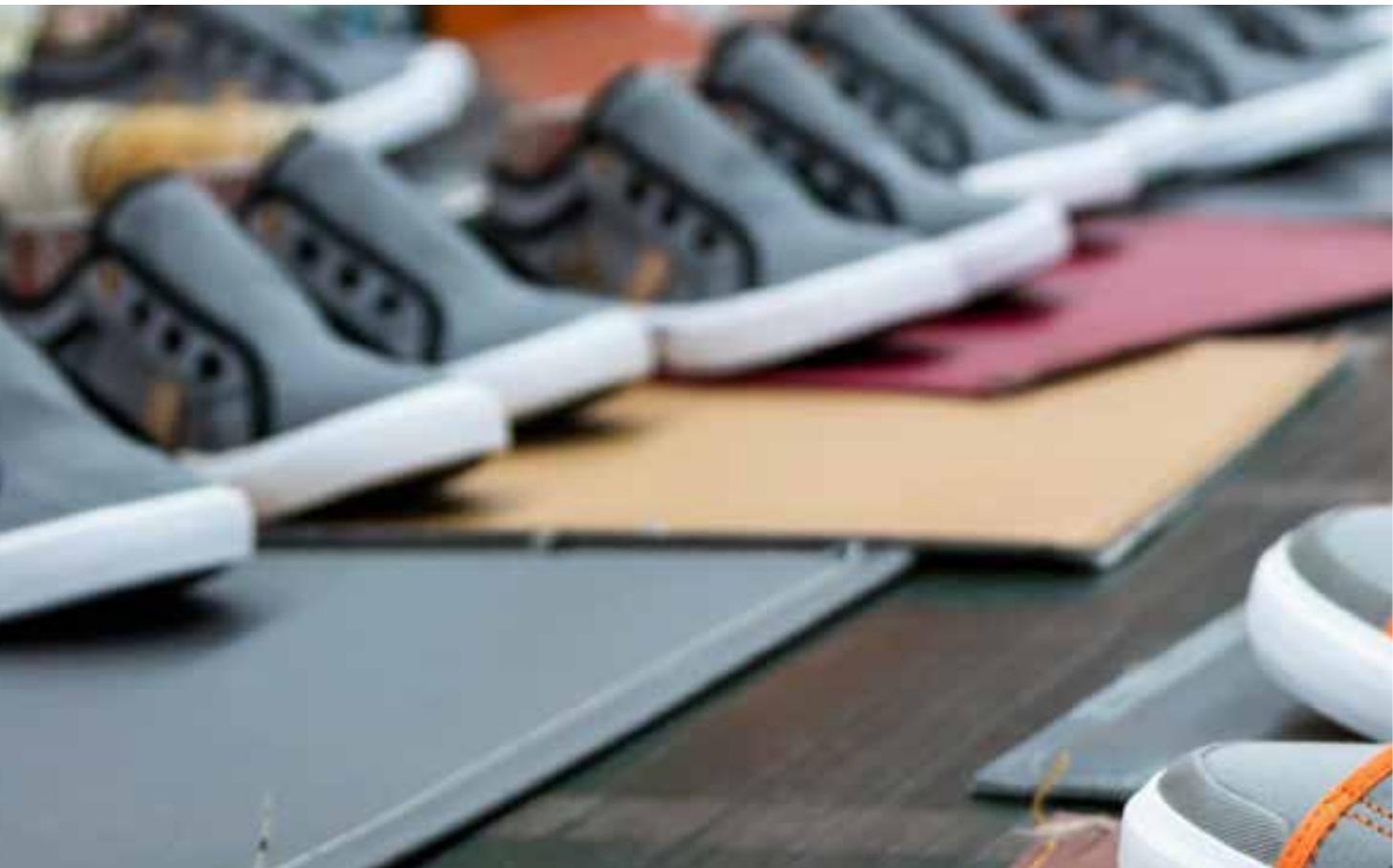




\section{Can suppliers claim that their products or services meet ISO 9001?}

No. The reference to ISO 9001 indicates that the supplier has a quality management system that meets the requirements of ISO 9001. As mentioned earlier, this should provide you with confidence in your supplier's ability to provide consistent, conforming products or services. ISO 9001 requires your supplier to monitor the levels of satisfaction of its customers (this includes you!), and to feed back this information in order to improve the effectiveness of its QMS.

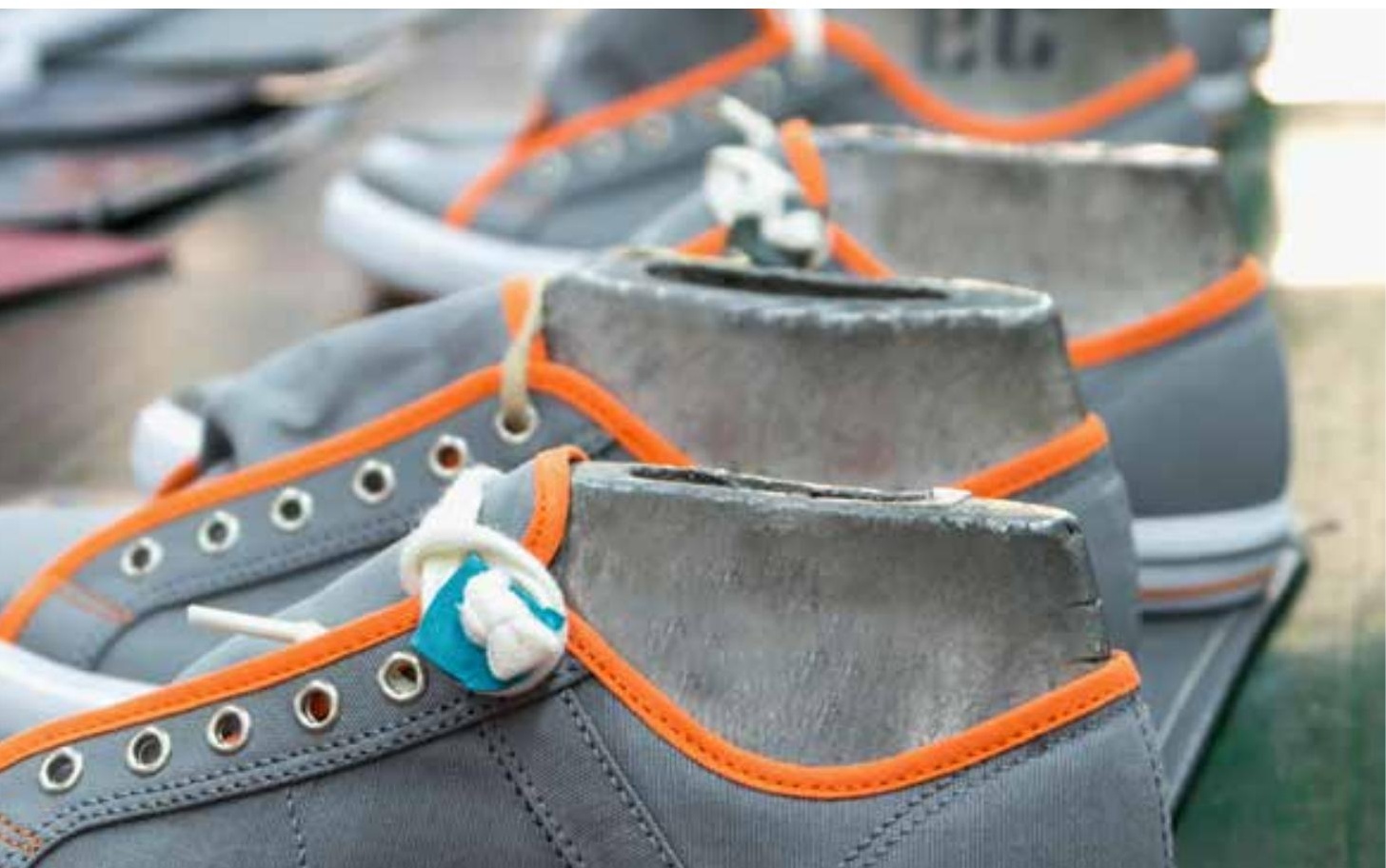




\section{What to do if things go wrong?}

In the event that you are not happy with specific products or services you receive, you should first of all bring this to your supplier's attention. You will typically do this via the normal technical and/or commercial communication channels that have been established. Your supplier is obliged to investigate your complaint and should take appropriate actions to avoid or reduce the chances of it happening again.

If, however, you are dissatisfied with the overall performance of your supplier (if for example they continue to provide non-conforming products and services, do not address your complaints, or are not taking appropriate corrective action), then this is an indication of problems in their quality management system.

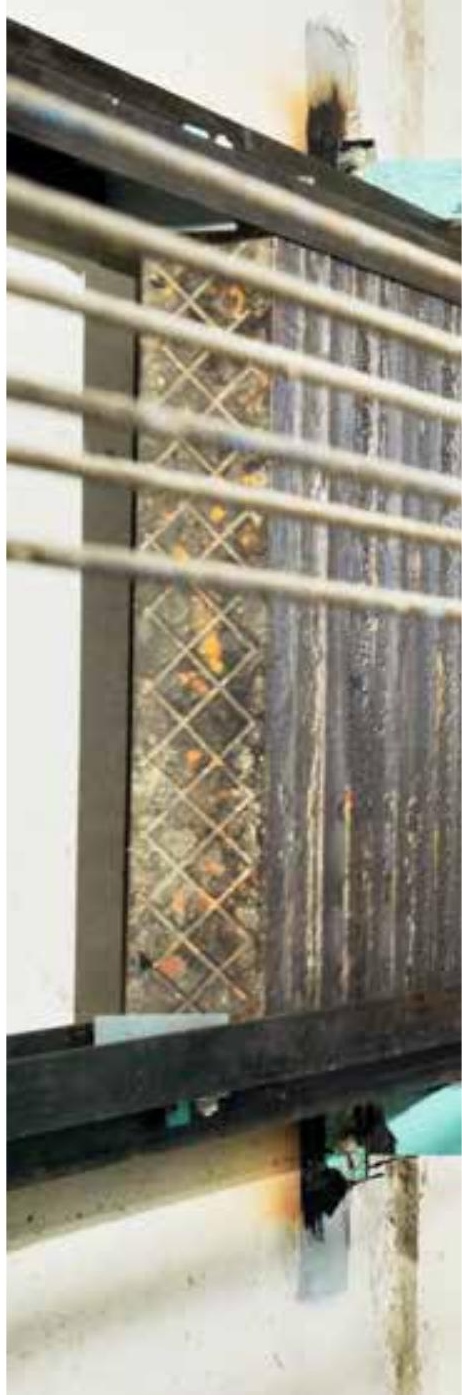




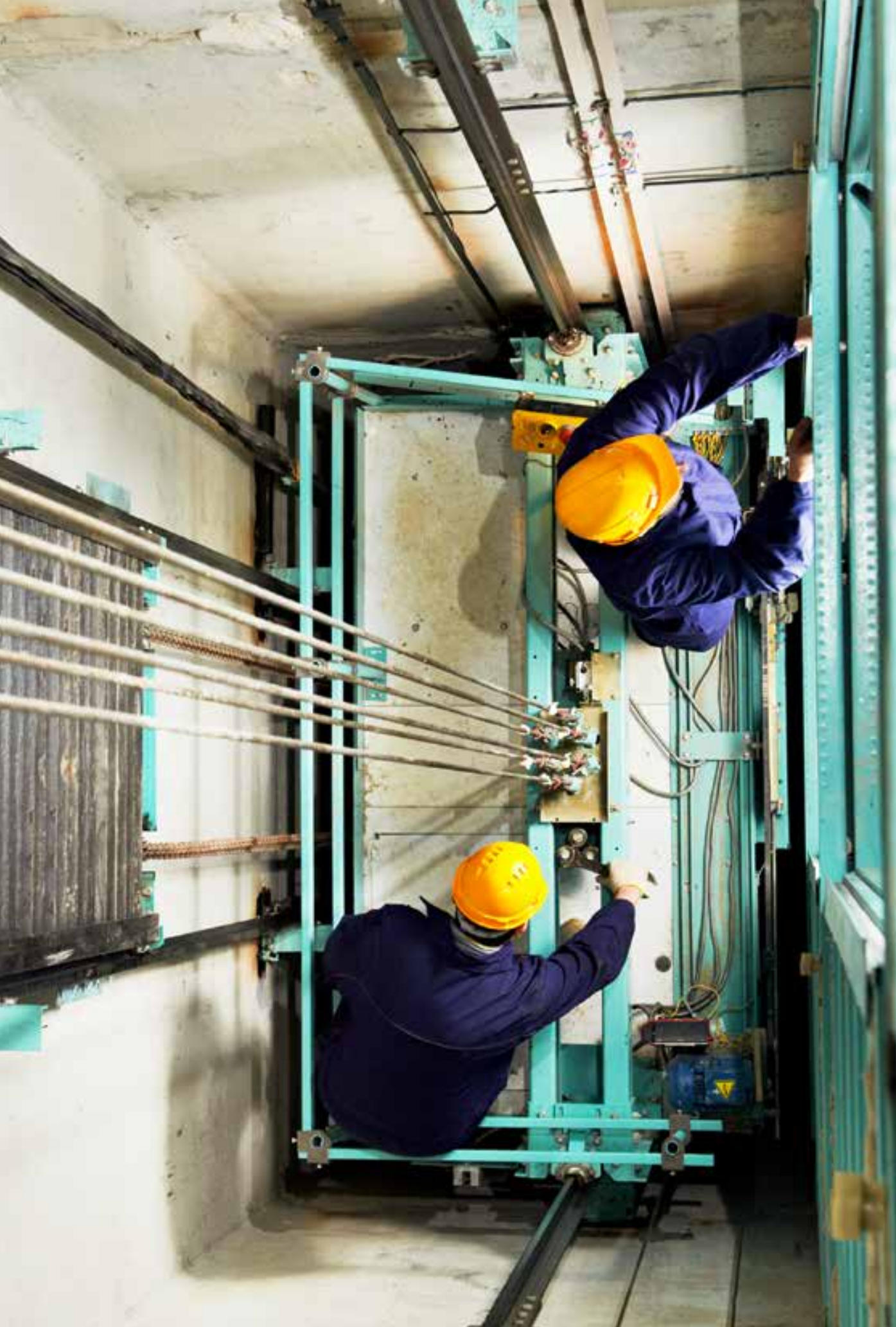


Depending on the responses you receive, you should be aware that you can escalate your complaint via the steps described below.

1. If your supplier has a QMS that meets ISO 9001 requirements, they are required to have established communication channels for monitoring customer satisfaction, obtaining customer feedback and dealing with complaints. You should make a formal complaint using these channels.
: 2. If you are still not satisfied with the response from your supplier, and if they are certified by an independent (third-party) certification body (registrar), you should bring the matter to the certification body's attention. You can find the certification body's name by looking at your supplier's certificate. The certification body will investigate the problems during their surveillance audits of your supplier's QMS, or, in critical cases, may decide to carry out an additional specific investigation. 
100

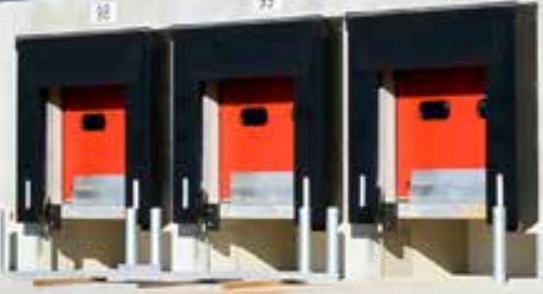

102

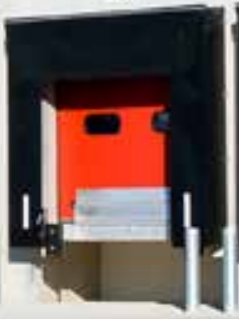

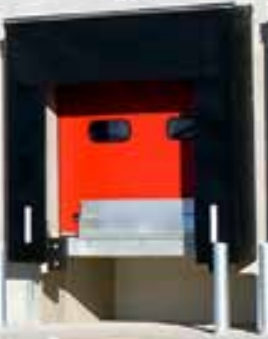

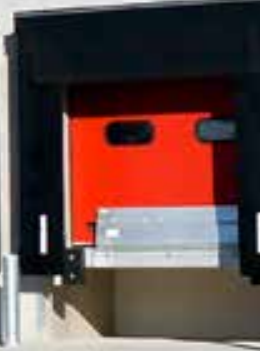

3. If you do not receive a satisfactory response from the certification body, and if it is accredited (see Figure 1), you should complain to the relevant accreditation body. Details of any such accreditation will appear on your supplier's ISO 9001 certificate. If you have difficulty in getting this information, you can consult the list of accreditation bodies that are members of the International Accreditation Forum on the IAF Website (www.iaf.nu).
4. If you feel that you have not received a satisfactory response from the accreditation body, and if it is a member of the International Accreditation Forum (see Figure 1), you can complain to the IAF (www.iaf.nu).

Remember that none of the above will affect your statutory rights as a purchaser and it may be appropriate to take legal action against your supplier instead of, or in parallel with, the above channels. The way in which you do this may vary from one country to another. 



\section{Summary}

ISO 9001 is a useful basis for organizations to be able to demonstrate that they are managing their business so as to achieve consistent (good!) quality products and services. There are several ways in which your suppliers can claim conformity to ISO 9001, and you need to ensure that the method chosen by your supplier provides you with the necessary degree of confidence.

If you are not satisfied with the performance of your supplier, you must provide them with the appropriate feedback. Learning from complaints helps organizations to improve their future performance - that is what ISO 9001 is about.

In addition to the abundant information on the ISO 9000 family in the Management standards section of the ISO Website, your national standards body is a further source of assistance.

NOTE: The above guidance was originally developed by the ISO 9000 Advisory Group, comprising representatives of ISO/TC 176 (the committee responsible for developing and maintaining the ISO 9000 family of standards), the ISO Committee on conformity assessment (ISO/CASCO), the ISO Committee on consumer policy (ISO/COPOLCO) and the International Accreditation Forum (IAF). It has since been updated to take into consideration the publication of ISO 9001:2015 in September 2015. 


\section{About ISO}

ISO (International Organization for Standardization) is an independent, non-governmental international organization with a membership of $162^{\star}$ national standards bodies. Through its members, it brings together experts to share knowledge and develop voluntary, consensus-based, market-relevant International Standards that support innovation and provide solutions to global challenges.

ISO has published more than $21000^{\star}$ International Standards and related documents covering almost every industry, from technology to food safety, to agriculture and healthcare.

For more information, please visit www.iso.org.

^January 2016

International Organization for Standardization

ISO Central Secretariat

Ch. de Blandonnet 8

Case Postale 401

CH - 1214 Vernier, Geneva

Switzerland

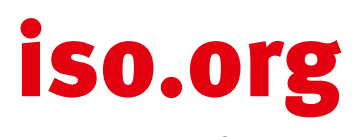

(c) ISO, 2016

All rights reserved 